\title{
The influence of large-scale climatic patterns on precipitation, temperature, and discharge in Czech river basins
}

\author{
Václav Š́pek ${ }^{1,2}$ \\ ${ }^{1}$ The Institute of Hydrodynamics of the Academy of Sciences of the Czech Republic, Pod Pat'akou 30/5, Prague, 16612 Czech Republic. \\ ${ }^{2}$ Department of Physical Geography and Geoecology, Faculty of Science, Charles University in Prague, Albertov 6, 128 43 Prague, Czech \\ Republic. \\ E-mail: sipek@ih.cas.cz
}

\begin{abstract}
The present study focuses on the possible influence of large-scale climatic patterns on precipitation, temperature, and discharge in two distinct river basins in the Czech Republic. The first one is a flat lowland basin of the Cidlina River and the second one represents a more mountainous type of climate (the Blanice River). The large-scale climatic patterns used comprise monthly averages of teleconnection patterns, sea level pressure values, and two geopotential heights $(850 \mathrm{hPa}$ and $500 \mathrm{hPa})$. The correlations for corresponding months and also up to a three months lead time were investigated. The relations concerning the corresponding months proved to be most reliable in the winter period of the year. The behaviour of both selected river basins with respect to these predictors is rather similar in character. However, higher values of correlation coefficients are reached in the case of the Cidlina River basin. Considering the prediction abilities with a certain lead time, the results seem to be more promising for the winter and spring periods in both basins. In the Cidlina River basin, they are likely to be beneficial also for the late summer and autumn period.
\end{abstract}

Keywords: Macro-scale climatic patterns; Cidlina River; Blanice River; Hydrometeorology.

Abbreviations: AO, Arctic Oscillation, BRB, Blanice River Basin, CRB, Cidlina River Basin, EA, East Atlantic Oscillation, EA/WR, East Atlantic-West Russian Oscillation, GHT500, geopotential height - $500 \mathrm{hPa}$, GHT850, geopotential height $-850 \mathrm{hPa}$, MAP, mean areal precipitation, MAT, mean areal temperature, MOI1, Mediterranean Oscillation Index 1 (Algiers and Cairo), MOI2, Mediterranean Oscillation Index 2 (Israel and Gibraltar), NAO, North Atlantic Oscillation, NSC, North Sea-Caspian Pattern, POL, Polar/Eurasian Pattern, Q, discharge, SCA, Scandinavian Pattern, SLP, sea level pressure, TPI, Trans Polar Index.

\section{INTRODUCTION}

Teleconnections between large-scale climatic patterns and meteorological records concerning particular areas of the world are a widely discussed topic. One of the main reasons for this investigation is the possible predictability of hydrometeorological variables based on large-scale circulation patterns or other characteristics of the atmosphere-land surface system. These variables, estimated with a certain lead time, might serve as the input dataset for hydrological models within hydrological forecasting systems. The question of the improvement and also increasing lead-time of hydrological forecasts is one of principal tasks of water management (Vörösmarty, 2002), especially in the context of possible changes in the hydrological regime (Hanel et al., 2012). Hence, investigation of the indices for long-range prediction of hydroclimatological variables is essential to assist future allocation of finite water resources (Wedgebrow et al., 2002).

The predictors that are usually used for this purpose can be represented by a variety of climatic indices and variables. The climate over Europe is related mainly to the North Atlantic sector, which is ordinarily captured by the North Atlantic Oscillation (NAO) (Hurrell, 1995). Thorough research has been conducted relating the NAO to temperatures (Pozo-Vázquez et al., 2001; Wang et al., 2011), precipitation (Uvo, 2003; Bartolini et al., 2009) or directly to discharges (Shorthouse and Arnell, 1999; Rimbu et al., 2002). Pekárová and Pekár (2007) recently investigated teleconnections of streamflow fluctuations in Slovakia with Quasi-Biennial Oscillation (QBO), Southern Oscillation (SO), NAO, and Arctic Oscillation (AO).
Other sources of valuable information on the basins' hydrometeorology are represented by the sea level pressure (SLP) (Steinschneider and Brown, 2011; Wilby et al., 2004) and the geopotential height (Oubeidillah et al., 2011; Rimbu et al., 2002). Various combinations of all these datasets that might further serve as potential predictors of the hydrological and meteorological time series are used as input data mainly for regression types of models (Folland et al., 2012; Svensson and Prudhomme, 2005). The main aim of this study is to assess possible connections between the various circulation indices and meteorological, as well as hydrological, datasets up to a lead time of three months. This will constitute a first step to construct a seasonal hydrological forecasting system in the conditions of the Czech Republic.

\section{DATA AND METHODS}

Two different river basins were used as areas of interest for the purpose of this study. Special attention was paid to the fact that these areas should represent climatically distinct zones. Thus, the first one is a flat lowland river basin, while the second one represents a more mountainous type of climate. The earlier is the Cidlina River basin (CRB) and the latter is the Blanice River basin (BRB) (Fig. 1).

The BRB may be split into two distinct parts separated by the Husinec Dam. This study deals with the hydrometeorological time series from the lower course below the Husinec Dam (the presence of which partially influences the rainfalldischarge relationship). Area of the BRB is $647 \mathrm{~km}^{2}$. The CRB 


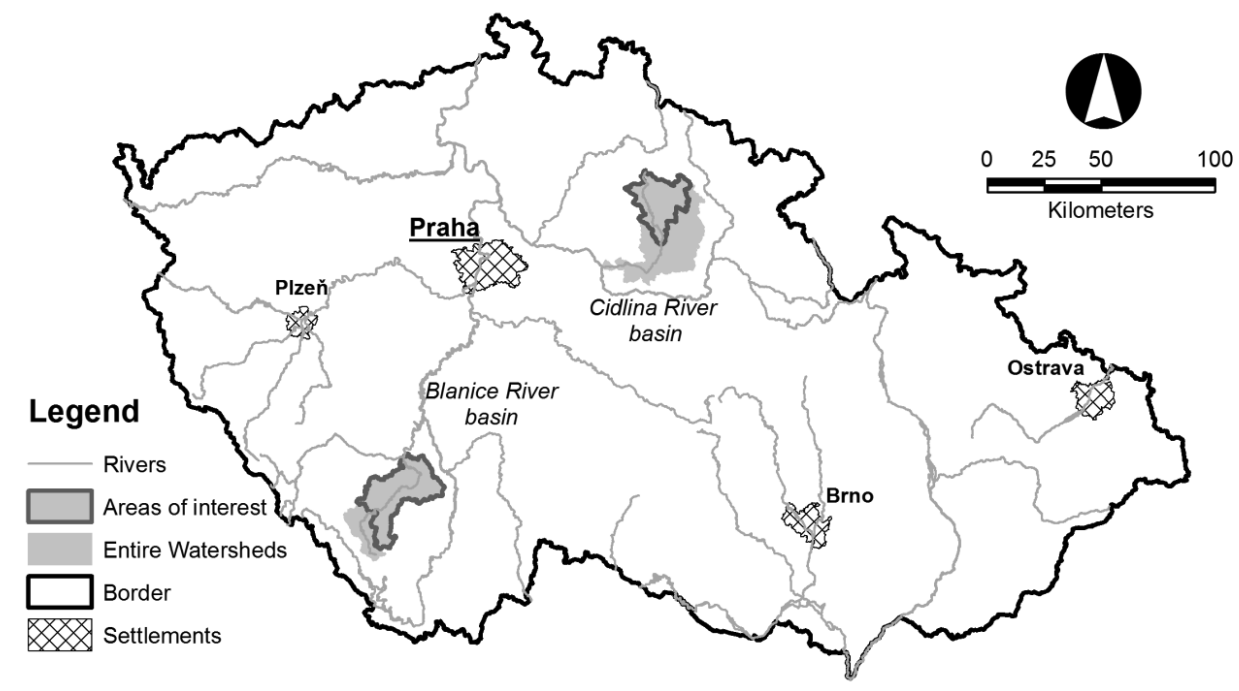

Fig. 1. Location of the studied river basins in the Czech Republic.

is located in sufficient distance from the BRB, which might lead to a different relation of the basin's hydrometeorology to the circulation indices or other large-scale meteorological variables. The studied part of the CRB to the Nový Bydžov gauging station has an area of $455 \mathrm{~km}^{2}$.

The climatic data sets were mostly selected to represent the climate over central Europe. Data sets can be divided into two major groups. First are the teleconnection patterns. Only the major patterns characterizing both the zonal and also meridional wind flow over Europe were considered. The NAO index (Hurrell, 1995), the North Sea-Caspian Oscillation (NSC) (Kutiel and Benaroch, 2002), Mediterranean Oscillation Indexes (MOI1 and MOI2) (Palutikof et al., 1996) and the Trans Polar Index (TPI) (Jones et al., 1999). These five patterns were obtained from the Climate Research Unit of the University of East Anglia website (CRU). The East Atlantic Pattern (EA), East Atlantic/West Russia (EA/WR), Scandinavian Pattern (SCAND), Polar/Eurasia (POL) defined by Barnston and Livezey (1987), and AO (Thompson and Wallace, 1998) are available at the National Centre for Environmental Protection/Climate Prediction Centre (NCEP/CPC) website. The raw data consisted of time series of monthly averaged values, which are available from January 1950. In the pre-processing, the cross correlation analysis between chosen patterns was conducted. It was found that some of the indices are analogous or connected. The most obvious is the relation between the NAO, $\mathrm{AO}$, MOI and EA, which is based on reflecting the strength of westerlies. Close relationship was also observed between the $\mathrm{EA} / \mathrm{WR}$ and the NSC, which are based on the same pressure pattern. Moreover, from January to June the SCA is inversely correlated with the NAO, AO and MOI, which corresponds to the role of blocking anticyclones over Scandinavia.

Second, the spatially distributed values of the sea level pressure (SLP), $500 \mathrm{hPa}$ geopotential height (GHT500), and 850 $\mathrm{hPa}$ geopotential height (GHT850) with a spatial resolution of 2.5 by 2.5 degrees longitude/latitude are used. The daily values of SLP, GHT500s, and GHT850s for the extraction window of the Eurasian Quarter-Sphere ( $90 \mathrm{~N}$ to $0 \mathrm{~N}, 90 \mathrm{~W}$ to $90 \mathrm{E}$ ) are available at the CRU website and originate from the NCEPNational Center for Atmospheric Research reanalysis project (Kalnay et al., 1996).

The hydrometeorological data for the BRB and the CRB basins are represented by the series of mean areal temperatures
(MAT), mean areal precipitation (MAP), and discharges. Both mean values are constructed by the method of Thiessen polygons using 12 precipitation stations for the BRB and 9 stations in the case of the CRB. Temperature data originate from three stations for each river basin. The data sets for the BRB are available for the period of 1980-2002. The study period for the CRB is restricted to the years 1990-2009. The time-series of discharges originate from the gauging stations in Heřmaň (BRB) and Nový Bydžov (CRB). All the data sets were obtained from the Czech Hydrometeorological Institute.

\section{RESULTS \\ Correlations for the same month}

Periods and areas of significant correlations (given by $95 \%$ percentile of the empirical probability distribution) are identified by the correlation analysis. Datasets span from 1980 to 2002 (BRB) and from 1990 to 2009 (CRB).

The strongest link between the circulation patterns and hydrometeorological conditions was found for the winter season (October-February). January and February have the highest correlation values of $0.6-0.8$ concerning the MAT. The correlations are mostly positive. Negative values are obtained in the case of EA/WR, SCA, TPI, NSC and POL patterns. A slightly closer relationship between temperatures and circulation patterns was found in the BRB; however, focusing on the precipitation amounts, higher correlations are found in the CRB (up to 0.75 using the MOI). The correlations with MAP are insignificant for the mountainous BRB.

Only weak and insignificant correlations are found in the warmer months of the year, where correlations with all hydrometeorological variables are mostly below 0.4 . The most obvious exception is the relationship between the MAT in both basins with the EA pattern (correlation coefficient is higher than 0.5 in the majority of months). The weakest correlation between EA and MAT is in July, when it is substituted by the strong relation of MAT to the NSC oscillation for both river basins. Additionally, June precipitation and also discharge values in the CRB might both be related positively to the SCA or negatively to the MOI and the NAO.

The relation between SLP and the hydrometeorology in both basins is different at different times of the year. In the warmer period of the year, no consistent pattern is observed in either 
basin. On the other hand, there is a distinct pattern from October to March for the MAT data in both basins. It is represented by the dipole of SLP, with one centre near Iceland and the second around the Canaries. This is consistent with the observed relations based on circulation patterns that represent the NAO-like scheme. This typical relationship is documented in Fig. 2. Nevertheless, considering the MAP and discharge, no obvious pertaining relationship with SLP was found in either basin even during the colder part of the year. Only in the case of the CRB, a field of negative correlations coefficients between SLP and MAP was located to the North Sea-southern Scandinavia region spanning from January to May and September to October. This was also documented by the values of SCA, NSC and EA/WR patterns.

Another possible variable which might be related to hydrometeorological datasets of the Czech Republic is represented by the geopotential height. Geopotential height might be roughly described as the height of certain pressure level above sea level, which means it also characterizes the atmospheric pressure patterns, although with more emphasis on its vertical extent. The GHT850 shows a similar pattern to the results from the SLP analysis. In both studied areas, the characteristic dipole is present considering the MAT data from October to March. These results correspond to the NAO-like pattern, as do the SLP datasets. Besides this particular dipole which is related to the MAT, an area of significant negative correlation with MAP is also present in the CRB. This area of negative correlation is located above southern Scandinavia, the Baltic and the North Sea and spans from January to May (Fig. 3). Similar link between MAP and the GHT850 datasets is present in September and October, but the centre of the field shifts southwards above Germany and becomes less pronounced. This link is evident in both studied basins, but it is less obvious in the BRB. The same characteristics might be generally applied to the GHT500 data, taking into account both areas, although there are minor differences. The most evident is the absence of the characteristic dipole (considering the relation of GHT500 data to MAT) at the end of the year. In the case of the GHT500 time series it can be observed only from January to March.

\section{Predicting the hydrometeorological variables from the large-scale climatic indices and variables}

When using circulation patterns, only a few relations between their values and hydrometeorological variables are beneficial. The correlation coefficients concerned with up to a 3 month lead time are depicted in Table 1. In the Table 1, all the correlations are significant at least at the $95 \%$ percentile level. The results for the BRB are generally worse than those obtained
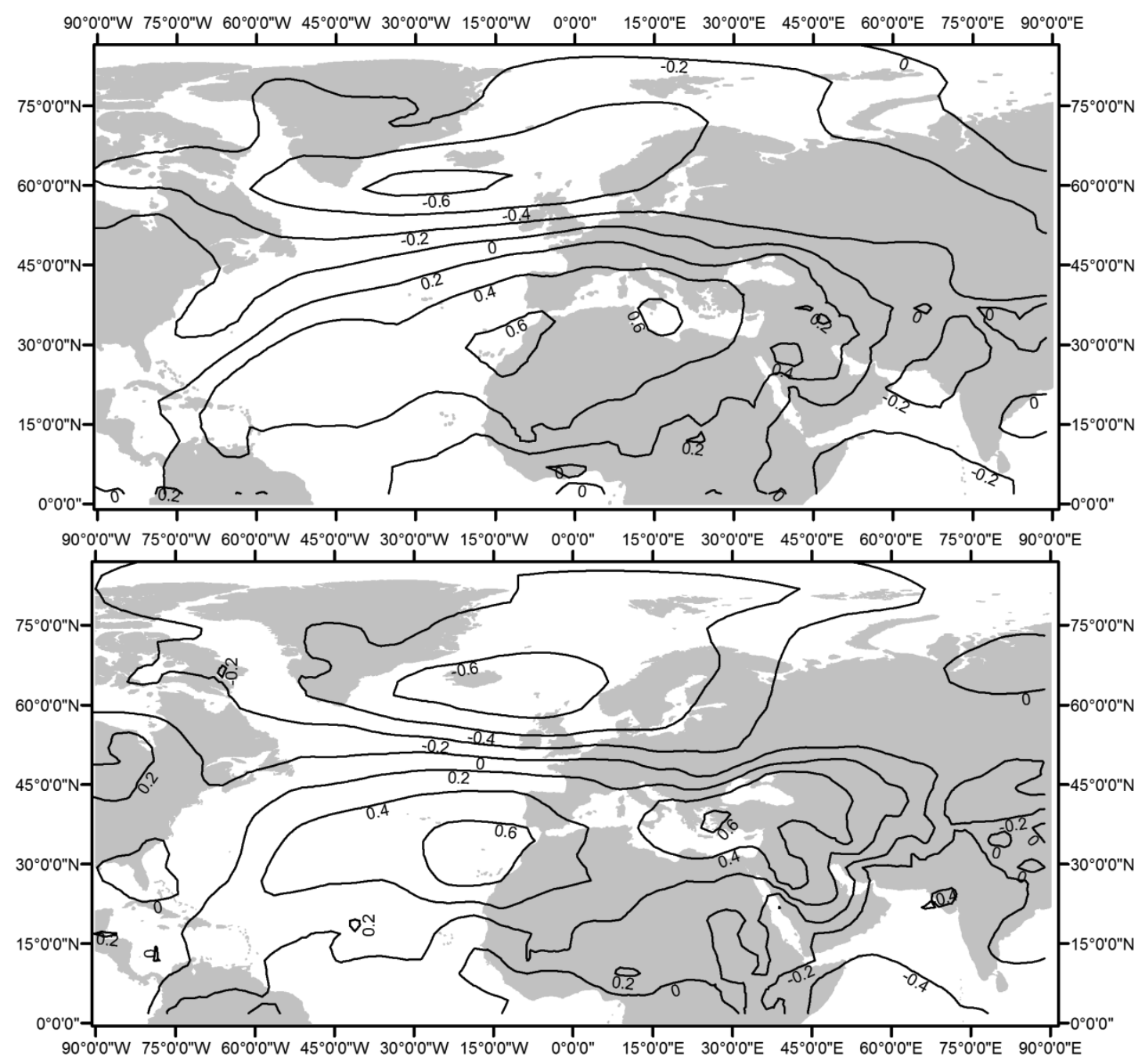

Fig. 2. Typical winter correlation coefficients pattern between December SLP and Blanice River MAT (upper panel) and Cidlina River (lower panel), respectively. 
The influence of large-scale climatic patterns on precipitation, temperature, and discharge in Czech river basins
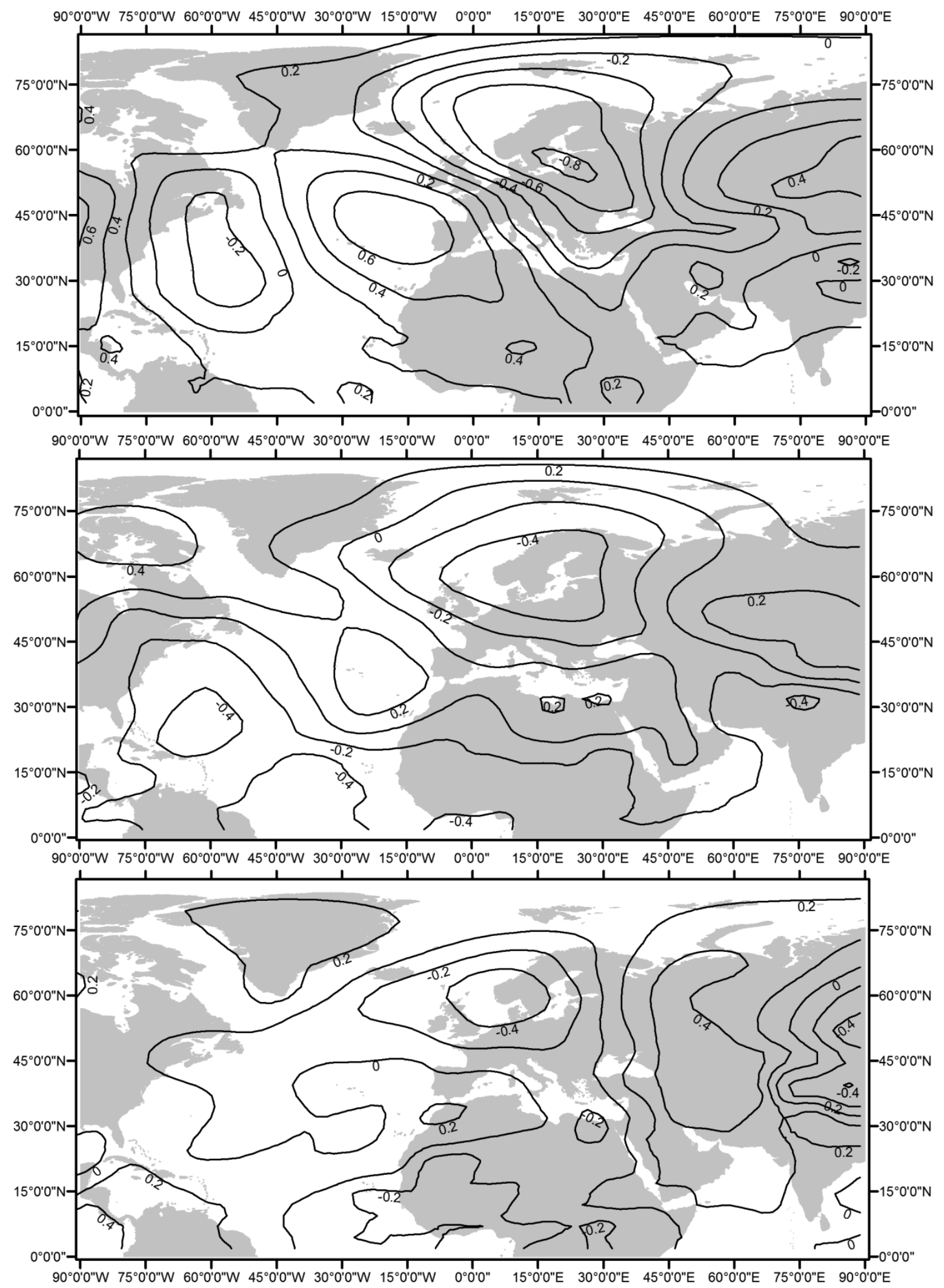

Fig. 3. Typical winter correlation coefficients pattern between January (upper panel), March (middle panel), and May (bottom panel) GHT850 and Cidlina River MAP. 
for the CRB, as the correlation coefficients are rather lower. The majority of closer relations between circulation values and hydrometeorological data occur in the period from October to March. Only a few possible predictors (moreover with longer lead times) can be found for the summer period in the BRB. Considering CRB, the number of predictors for the summer period is higher for the precipitation and discharge estimation. As shown in Table 1, the winter predictions are mostly based on the NAO, AO and EA oscillations, implying the prevailing influence of the North Atlantic climate on the hydrometeoro- logical variables in the Czech river basins in the winter. During the summer the influence of the second group of oscillations characterizing the meridional air masses movement represented e.g. by EA/WR, MOI or SCA is also detected. Examples of atmospheric circulation values and MAP for both basins in January and July are illustrated in Fig. 4. Although the correlation coefficients values are not negligible, it may be deduced that sometimes the higher value of one predictant does not correspond to the desired (higher or lower) value of the predictor.

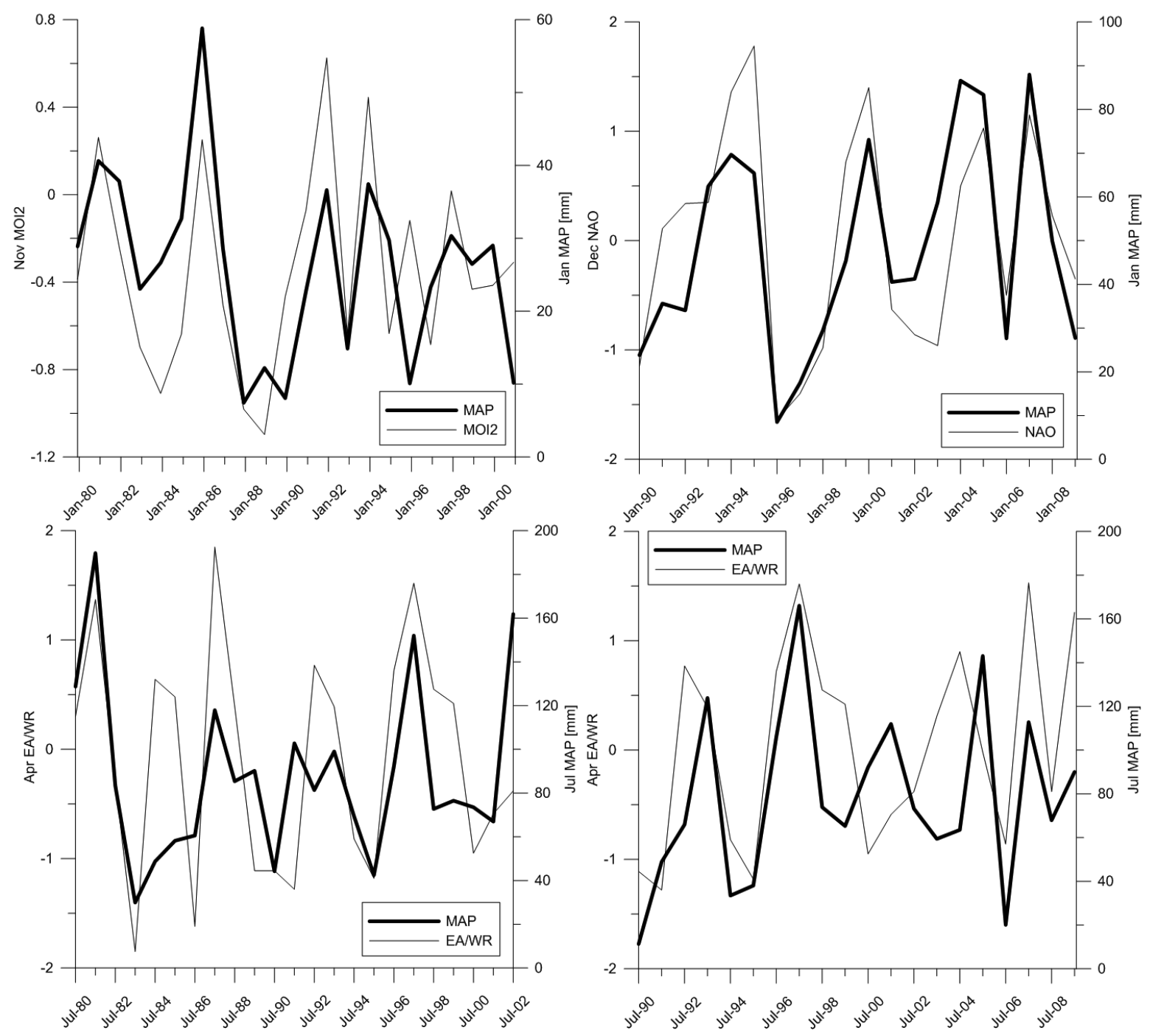

Fig. 4. Relations between circulation patterns and MAP for the Blanice River (left two panels) and Cidlina River (right two panels) in January and July.

In the case of spatially distributed climatological variables, the correlation analysis was performed for the entire study domain. However, for the prediction purposes only the grids of maximum correlation coefficients were used. The use of the SLP dataset for prediction of the basins' hydrometeorology is limited. Although the correlation coefficient might reach values of \pm 0.7 , no pattern is obvious for the lead times from one to three months. The climate data and discharges could be predicted better for the CRB than for the BRB. The best predictive abilities are therefore constrained to the $\mathrm{CRB}$ area, namely to the estimation of discharge in the late summer and autumn months (August, October and November) and MAP in winter months (January-March). The discrepancy between predictive ability for Q and MAP in October and November is caused by the weaker correlation observed even in the measured data. Certain correlations are found, but they are not that significant. Correlation coefficients range from $0.3-0.5$. Therefore they are not listed in Table I. The correlation coefficients for chosen months are depicted in Table 1. For the BRB, no effective relationship between climate and the SLP was found. 
The influence of large-scale climatic patterns on precipitation, temperature, and discharge in Czech river basins

Table 1. Useful predictors of river basins" hydrometeorology.

\begin{tabular}{|c|c|c|c|c|c|c|c|c|c|c|}
\hline & & Predictor & $\begin{array}{c}\text { January } \\
\text { Lead }\end{array}$ & $\mathrm{CC}$ & Predictor & $\begin{array}{c}\text { February } \\
\text { Lead }\end{array}$ & $\mathrm{CC}$ & Predictor & $\begin{array}{c}\text { March } \\
\text { Lead }\end{array}$ & $\mathrm{CC}$ \\
\hline \multirow{10}{*}{ 祃 } & \multirow{5}{*}{ 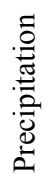 } & Dec NAO & 1 & 0.79 & Jan SST & 1 & 0.84 & Dec SLP & 3 & -0.65 \\
\hline & & Dec GHT 850 & 1 & -0.65 & Nov GHT 500 & 3 & -0.81 & Dec NSC & 3 & -0.62 \\
\hline & & Dec SLP & 1 & -0.66 & Dec SLP & 2 & -0.71 & & & \\
\hline & & Dec SLP & 1 & 0.70 & Nov SLP & 3 & 0.72 & & & \\
\hline & & Nov GHT 500 & 2 & -0.68 & Nov GHT 850 & 3 & 0.70 & & & \\
\hline & \multirow{5}{*}{ 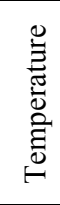 } & Dec SLP & 1 & -0.74 & \multirow{5}{*}{ Nov SLP } & \multirow{5}{*}{3} & \multirow{5}{*}{0.72} & Feb POL & 1 & -0.52 \\
\hline & & Dec SLP & 1 & 0.68 & & & & Jan SCA & 2 & -0.61 \\
\hline & & Nov SPL & 2 & -0.61 & & & & Jan GHT 500 & 2 & -0.66 \\
\hline & & Dec GHT 850 & 1 & -0.74 & & & & Feb EA & 1 & 0.54 \\
\hline & & Dec GHT 850 & 1 & 0.71 & & & & & & \\
\hline
\end{tabular}

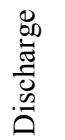

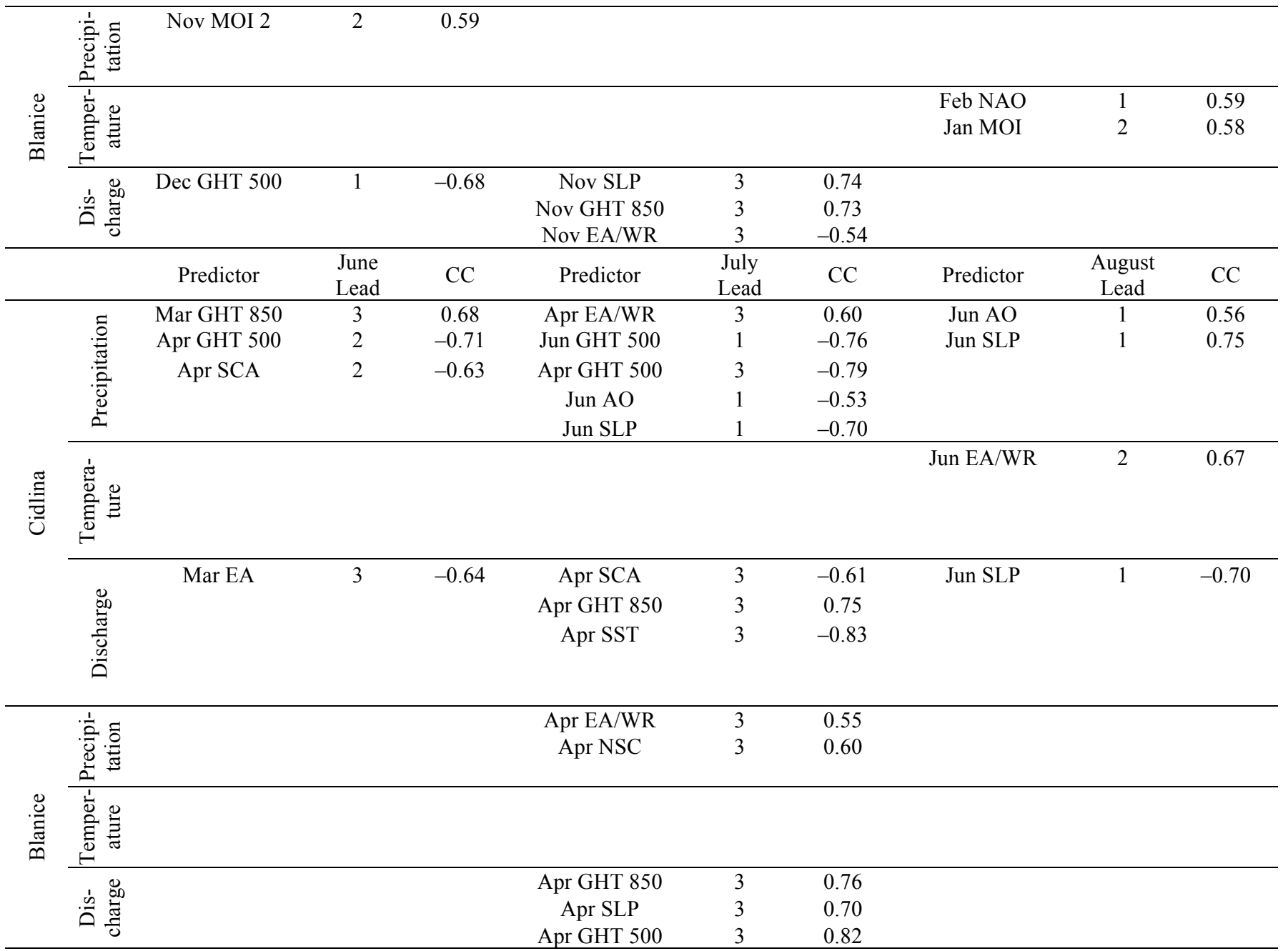

The last variables tested for their potential predicting skill were GHT500 and GHT850. Using both geopotential heights, no long-lasting patterns that span more than one month were observed. GHT500 can be mainly related to the discharge in the $\mathrm{BRB}$, with the correlation coefficients only rarely reaching values of $0.6-0.7$. The most useful relations are between the August GHT500 over Alps and the average September discharge and the April GHT500 from the area of the Shetland Islands and July MAT (Fig. 5). A higher amount of helpful correlations is available for the CRB. The most useful ones are for selected months recorded in Table 1 . The majority of them are limited to the estimation of precipitation or discharge. The GHT850 datasets represent a beneficial predictor of the CRB discharges and precipitation amounts. The BRB basin climatology could be even less well predicted by the GHT850 da taset as only three beneficial links between GHT850 and discharges were found. 

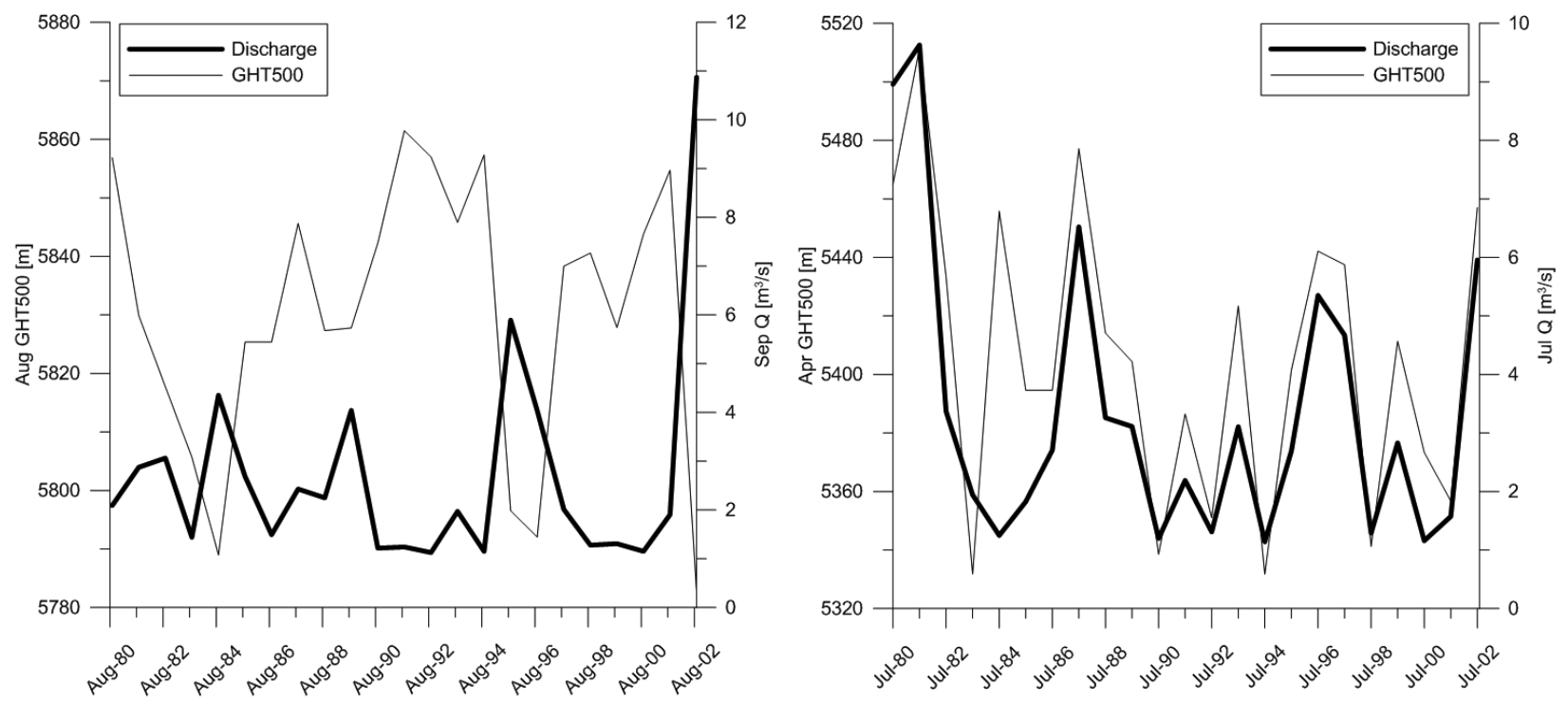

Fig. 5. The relations between GHT500 and a) September discharge -1 month lead (left panel) and b) July temperature -3 months lead (right panel) for the Blanice River.

\section{CONCLUSIONS AND DISCUSSION}

The climatic oscillations proved to be linked to the basins' hydrometeorology more tightly in the late autumn and winter months (October-March). The highest correlations were found especially for January and February, which corresponds to the finding of Pozo-Vázquez et al. (2001), Cahynova and Huth (2009) and Brázdil et al. (2009). The correlation between precipitation and NAO values is not that significant even in the above mentioned winter period, as previously shown by Bartolini et al. (2009) or Marshall et al. (2001). Shorthouse and Arnell (1999) showed that it may be difficult to link the NAO directly to discharges in the Central European region, which was also proved in this study. According to winter (JanuaryMarch) correlations, the circulation patterns could be split into two groups. The first was represented by NAO, AO, MOI and EA, which are correlated with the basins' datasets rather positively (most pronouncedly with MAT but also with MAP and discharges). Conversely, the second group which contains EA/WR, NSC, SCA and POL, is mostly negatively correlated to the basins' hydrometeorology. The reason is that these teleconnections characterize a similar pattern, which is based on the east-west dipole considering also the Eurasian continental pressure values. The rest of the teleconnections characterize instead the pressure patterns over the Atlantic Ocean or the Mediterranean Sea. Generally, the connection between the oscillation data and the basins' hydrometeorology has a similar pattern in both areas. However, the relations are less evident in the case of the BRB, which could be attributed to the possible influence of the nearby mountain range that plays a significant role in the basin's climate. Considering possible use of oscillation datasets for predicting purposes, the climate data and discharges could also be better predicted for the CRB basin than for the BRB. In the BRB, the winter and spring periods are the only periods of the year in which the weather could be estimated in advance. The NAO/AO/MOI/EA group of oscillations should be used in this period. The winter and spring predictability is valid also for the CRB. In addition, the summer weather might be estimated in this basin; however, based on the $\mathrm{EA} / \mathrm{WR} / \mathrm{NSC} / \mathrm{SCA} / \mathrm{POL}$ group of patterns.
A few regularities were observed when relating the values of the SLP, GHT 500 and GHT 850 to the corresponding months' hydrometeorological datasets. Distinct pattern from October to March is observed in both basins for the MAT data. This is represented by the dipole of SLP with one centre near Iceland and the second around the Canaries, which is consistent with the NAO scheme. Moreover, the MAP records from the Cidlina River basin could be negatively related to SLP values in southern Scandinavia and the North Sea in the periods of JanuaryMay and September-October. The geopotential data generally correspond to the NAO pattern observed in SLP. Using these three predictor datasets for estimating the weather in advance is of limited use, because persistent correlation patterns are not identified and they seem to be randomly distributed. Generally, it might be stated that they are more suitable for the flat lowland CRB, where a few relations were found.

The physical explanation of the relations is troublesome, namely because of their temporal and spatial character. However, the vast majority of predictive relations is restricted to the area of the North Atlantic region or southern Scandinavia. Thus, they characterize the pressure field in this region, which in turn influences the position and the strength of the jet stream (Hannachi et al., 2011). Jet stream characteristics have profound influence on the weather conditions not only in the Czech Republic, but over entire Europe (Franzke et al., 2011; Francis and Vavrus, 2012). The link between jet stream position and the large scale climatic patterns was showed, e.g. by Woolings et al. (2011) or Woolings and Blackburn (2012).

From the hydrological point of view, identified relations offer the possibility of introducing a seasonal probabilistic hydrological forecasting system which would be most reliable for predicting the period of high spring discharges in both river basins. In the case of the flat lowland region of the CRB it is also likely to be beneficial for the late summer and autumn periods which are prone to water deficiency in this particular area.

Acknowledgements. The research project has been funded by the Grant Agency of the Academy of Sciences of the Czech Rep. under project No. IAA300600901. The authors acknowledge the financial assistance on this project. 


\section{REFERENCES}

Barnston, A.G., Livezey, R.E., 1987. Classification, seasonality and persistence of low-frequency atmospheric circulation patterns. Mon. Wea. Rev., 115, 1083-1126.

Bartolini, E., Claps, P., D’Odorico, P., 2009. Interannual variability of winter precipitation in the European Alps: relations with the North Atlantic Oscillation. Hydrology and Earth System Sciences, 13, 17-25.

Brázdil, R., Chromá, K., Dobrolný, P., Tolasz, R., 2009. Climate fluctuations in the Czech Republic during the period 1961-2005. International Journal of Climatology, 29, 223242.

Cahynova, M., Huth, R., 2009. Changes of atmospheric circulation in central Europe and their influence on climatic trends in the Czech Republic. Theoretical and Applied Climatology, 96, 57-68.

Folland, C.K., Scaife, A.A., Lindesay, J., Stephenson, D.B., 2012. How potentially predictable is northern European winter climate a season ahead? International Journal of Climatology, 32, 801-818.

Franzke, C., Woolings, T., Martius, O., 2011. Persistent circulation regimes and preferred regime transitions in the North Atlantic. Journal of Atmospheric Sciences, 68, 2809-2825.

Francis, J.A., Vavrus, S.J., 2012. Evidence linking Arctic amplification to extreme weather in mid-latitudes. Geophysical Research Letters, 39, L06801.

Hanel, M., Vizina, A., Máca, P., Pavlásek, J., 2012. A multimodel assessment of climate change impact on a hydrological regime in the Czech Republic. Journal of Hydrology and Hydromechanics, 60, 152-161.

Hannachi, A., Woolings, T., Fraedrich, K., 2011. The North Atlantic jet stream: a look at preferred positions, paths and transitions. Quarterly Journal of the Royal Meteorological Society, 138, 862-877.

Hurrell, J.W., 1995. Decadal trends in the North Atlantic Oscillation and relationships to regional temperature and precipitation. Science, 269, 676-679.

Jones, P.D., Salinger, M.J., Mullan, A.B., 1999. Extratropical circulation indices in the Southern Hemisphere based on station data. International Journal of Climatology, 19, 13011317.

Kalnay, E., Kanamitsu, M., Kistler, R., Collins, W., Deaven, D., Gandin, L., Iredell, M., Saha, S., White, G., Wollen, J., Zhu, Y., Leetmaa, A., Reynolds, R., Chelliah, M., Ebisuyaki, W., Higgins, W., Janowiak, J., Mo, K.C., Ropelewski, C., Wang, J., Jenne, R., Joseph, D., 1996. The NCEP/NCAR 40years reanalysis project. Bull. Amer. Meteor. Soc., 77, 437471.

Kutiel, H., Benaroch, Y., 2002. North Sea Caspian Pattern (NCP) - an upper level atmospheric teleconnection affecting the eastern Mediterranean: Identification and definition. Theoretical and Applied Climatology, 71, 17-28.

Marshall, J., Kushnir, Y., Battisti, D., Chang, P., Czaja, A., Dickson, R., Hurrell, J., McCartney, M., Saravan, R., Visbeck, M., 2001. North Atlantic climate variability - phenomena, impacts and mechanisms. International Journal of Climatology, 21, 1863-1898.

Oubeidillah, A.A., Tootle, G.A., Moser, C., Piechota, T., Lamb, K., 2011. Upper Colorado River and Great Basin streamflow and snowpack forecasting using Pacific oceanicatmospheric variability. Journal of Hydrology, 410, 169177.

Palutikof, J.P., Conte, M., Casimiro Mendes, J., Goodess, C.M., Espirito Santo F., 1996. Climate and Climate Change. In: Brandt, C.J., Thornes, J.B., (eds). Mediterranean Desertification and Land Use. John Wiley and Sons, London.

Pekárová, P., Pekár, J., 2007. Teleconnections of Inter-Annual Streamflow Fluctuation in Slovakia with Arctic Oscillation, North Atlantic Oscillation, Southern Oscillation, and QuasiBiennial Oscillation Phenomena. Advances in Atmospheric Sciences, 24 (4), 655-663.

Pozo-Vázquez, D., Esteban-Parra, M.J., Rodrigo, F.S., CastroDíez, Y., 2001. A study of NAO variability and its potential non-linear influences on European surface temperature. Climate Dynamics, 17, 701-715.

Rimbu, N., Boroneant, C., Buta, C., Dima, M., 2002. Decadal variability of the Danube river flow in the lower basin and its relation with the North Atlantic Oscillation. International Journal of Climatology, 22, 1169-1179.

Shorthouse, C., Arnell, N., 1999. The effects of climatic variability on spatial characteristics of European river flows. Physical and Chemistry of Earth (B), 24 (1-2), 7-13.

Steinschneider, S., Brown, C., 2011. Influences of North Atlantic climate variability on low-flows in the Connecticut River Basin. Journal of Hydrology, 409, 212-224.

Svensson, C., Prudhomme, C., 2005. Prediction of British summer river flows using winter predictors. Theoretical and Applied Climatology, 82, 1-15.

Thompson, W.W.J., Wallace, J.M., 1998. The Arctic Oscillation signature in the wintertime geopotential height and temperature fields. Geophysical Research Letters, 25(9), 12971300.

Uvo, C.B., 2003. Analysis and regionalization of northern European winter precipitation based on its relationship with the North Atlantic oscillation. International Journal of Climatology, 23, 1185-1194.

Vörösmarty, J.C., 2002. Global change, the water cycle, and our search for Mauna Loa. Hydrological Processes, 16, 135139.

Wang, G., Dolman, A.J., Alessandri, A., 2011. A summer climate regime over Europe modulated by the North Atlantic Oscillations. Hydrology and Earth System Sciences, 15, 5764.

Wedgebrow, C.S., Wiley, R., Fox, H.R., O'Hare, G., 2002. Prospects for seasonal forecasting of summer drought and low river flow anomalies in England and Wales. International Journal of Climatology, 22, 219-236.

Wilby, R., Wedgebrow, C.S., Fox, R.H., 2004: Seasonal predictability of the summer hydrometeorology of the River Thames, UK. Journal of Hydrology, 295, 1-16.

Woolings, T., Pinto, J.G., Santos, J.A., 2011. Dynamical evolution of North Atlantic ridges and poleward jet stream displacements. Journal of Atmospheric Sciences, 68, 954-963.

Woolings, T., Blackburn, M., 2012. The North Atlantic jet stream under climate change and its relation to the NAO and EA patterns. Journal of Climate, 25, 886-902.

Received 21 December 2012 Accepted 21 September 2013 